\title{
Upper Secondary School and University Level Students' Perceptions of Extractions in Context: Experiences from a Simple Laboratory Experiment
}

Tuomas M. A. Nurmi1*, Juha H. Siitonen*2

1. Department of Chemistry, University of Jyvaskyla, P.O. Box 35, FI-40014 Jyväskylä, Finland

tuomas.m.a.nurmi@jyu.fi

2. Department of Chemistry, Rice University, 6500 Main Street, Houston, Texas 77030, United States

juha.siitonen@rice.edu

\begin{abstract}
We discuss the pedagogical challenges associated with the current way of introducing extraction in upper secondary school chemistry education. These challenges were identified based on a survey of upper secondary school textbooks and verified through a questionnaire study. To address the identified challenges, we introduce a simple and effective extraction experiment which focuses on building a deeper conceptual understanding of extraction processes. The operationally simple extraction experiment and the accompanying questionnaire revealed that while students have several chemical misconceptions arising from the use of superficial everyday examples, they have all the necessary knowledge for developing a deeper understanding of chemistry. Providing a suitable experimental platform for developing and re-evaluating their knowledge allows the students to reasonably independently re-conceptualize their thinking toward a more coherent view of the surrounding world and the related scientific models. Furthermore, the work analyses the challenges that can be encountered when using everyday examples in teaching, and demonstrates that student-discovered examples of chemical systems can be a powerful method for generating meaningful and relevant ways to introduce scientific phenomena in STEM education.
\end{abstract}

\section{Introduction}

The goal of Finnish upper secondary chemistry education is to develop students' capabilities in scientific thinking and building a modern world-view as a part of multidisciplinary and multi-faceted skills and know-how. (Finnish National Agency for Education, 2019) An analysis of Finnish upper secondary school chemistry curriculum (Finnish National Agency for Education, 2019) and the supplementary material thereof reveals that extraction is often discussed only as a separation method. Despite the global push (DeBoer 2000, King 2012, Childs et al 2015) to introduce chemistry, in particular environmental chemistry, in a wider context as the central science to the syllabus, it is rather surprising that no connection to the socio-environmental aspects of extraction or equilibrium systems are made. The examples of extraction discussed in upper comprehensive school (IImiö 7-9, Sanoma Pro 2016) and upper secondary school textbooks (Reaktio 1, Tammi 2009; Mooli 1-2, Otava 2021) are often linked to student's daily lives, with examples such as brewing coffee or tea showing up prominently. One book series (Mooli 1, Otava 2016; Mooli 1-2, Otava 2021) carries an example of liquid-liquid extraction of berries, with a photograph dominated by a separatory funnel and other laboratory equipment relatively unfamiliar to the students. While these are examples of extractions, the few sentences associated with them give a very shallow 
introduction, which makes it hard for the students to connect to the larger context of what an extraction process is: the transfer of material from one phase to another, leading to an equilibrium distribution. This definition can easily be lost in the provided concrete examples and lead to students being confused as to what constitutes an extraction process. Consider one the most widely used examples for extraction: brewing coffee. While extraction is a part of the system as whole, several other processes such as filtration and boiling are also involved. This further highlights the issue that arises from teaching extraction using macro-level (Johnstone 1991) examples: in macroscopic examples, which consist of multi-process systems, it is hard for students to comprehend and separate which process is actually relevant for the discussion, and how the different processes are interconnected. With the development of misconceptions being an ever-present challenge in chemical education (Barker 2000, Barke et al 2009, Sarıtaş et al 2021), it is not hard to foresee confusion arising when brewing coffee is presented as the example of an extraction, even though the most clearly observable sub-processes in a coffee machine are the audible boiling of the water, and filtration with the filter paper, which is supplied by the user manually. Such use of multi-process examples may easily result in a cognitive overload, and as a result the student either cannot develop a conceptual understanding on what an extraction process actually is, or develops a misconception based on their interpretation. (Sweller 1994, Cook 2006, Milenković et al 2014, Nyachwaya \& Gillaspie 2016)

When assessing perspectives broader than the everyday activities of students, one of the most societally important aspects of chemistry is the understanding of how chemical principles contribute to the protection and preservation of the environment. As characterized by Rockström et al. (2009) chemical pollution belongs in the nine planetary boundaries, which must be kept in bounds for humanity to be able to live sustainably. The topic is well recognized in scientific research and also in public discourse, and continuous research goes on on both persistent organic pollutants, such as DDT and PCBs (Lohmann et al 2007, Herzig et al 2019), and emerging organic pollutants, e.g. drugs and pharmaceuticals, their metabolites and transformation products, surfactants, and endocrine disruptors (Bolong et al 2009, Nurmi et al 2019). While the fundamental concept of an extraction and the associated equilibria of chemicals migrating between phases is routinely used in environmental chemistry to understand the fates of pollutants and their environmental behaviour (e.g., degradation, bioaccumulation, and metabolism), there is a clear lack of connection: extractions outside of their use as a separation technique are rarely discussed in upper secondary school chemistry, despite their importance in a well-rounded education and scientific literacy.

The unfocused nature of, and scarcity in themes in, examples that are used to introduce extractions is rather surprising, since extraction is, in itself, highly interconnected to other fundamental chemical concepts. On a submicroscopic level (Johnstone 1991) it can be used to discuss intramolecular interactions, on a symbolic level equilibrium processes, and in an even broader perspective, the conservation of mass and the very nature of chemical substances. All of these can be developed further to models which describe extractions, allowing such experiments to have a wider conceptual reach to chemistry students. In this manuscript we describe a tangible laboratory experiment as a framework for introducing extractions in a wider context to upper secondary school students. Our goal in designing thereof was to make it easy for students to make clear observations and limit the experimental complexity associated with using unfamiliar laboratory glassware, such as 
separatory funnels. (Horowitz 2003, Loyo-Rosales et al 2006) We made this choice as student's focus on fundamental chemistry is easily shifted toward the mechanical task of building complex pieces of apparatus. While such mechanical skills are important in science, laboratory experiment's practical complexity can misguide students from the deeper fundamental phenomenon. (Gabel 1999, Reid \& Shah 2007) Other examples of such experimental simplification paradigm have recently been published by Orzolek \& Kozlowski (2021) as they developed an acid-base experiment as a part of developing at-home laboratory methods for COVID-19 pandemic, and by Williamson (2021) on demonstrating a minimal liquid-liquid equilibrium system. In concurrence with the experiment, we used a questionnaire to collect background perceptions of students' understanding of extractions and their interconnectivity with other topics in chemistry and other disciplines, and see how they were affected when completing the experiment. We also discuss our key findings in what we call student-led concept discovery, and other important insights into how extractive processes are feasible tools for providing intra- and interdisciplinary connectivity within chemistry studies.

\section{Methods}

\section{Description of the laboratory experiment}

In order to provide such highly sought after meaningful scaffolding for students to understand the larger context and interconnectivity of extraction processes, we sought to develop a tangible and operationally simple laboratory experiment to address many of existing discrepancies. The design criteria for the experiment were 1) ease of carrying the experiment out with simple materials 2 ) availability of materials 3 ) easy-to-make and clear observations 4) macroscopically showing molecules moving from one phase to another 5) demonstrating that not all extraction processes are quantitative 6) showing how weak interactions can be used to predict the extraction efficiency.

Following the above-mentioned criteria, we designed a qualitative experiment loosely based on the standardized partition coefficient test (OECD 1995) that is used for determining the 1-octanol-water-partitioning coefficients $\left(\mathrm{P}_{\mathrm{ow}}\right.$, or $\left.\mathrm{K}_{\mathrm{ow}}\right)$. In the experiment, which is outlined in Figure 1, the iterative partitioning of methylene blue dye between 1-octanol and water is studied qualitatively using a set of test-tubes and pipettes. After each extraction of methylene blue from 1-octanol with water, the aqueous layer is separated and retained for immediate visual comparison. (For detailed teacher and student experimentals see the ESI 1 and 2). After screening a set of organic dyes, methylene blue was found to have the most favorable partitioning coefficient, where the relative concentration difference between 1 -octanol and water is large enough to be easily visually observed, yet not too large allowing multiple successive extraction rounds. Importantly, the extraction can be carried out as a purely qualitative one, without the need for calculating the partition coefficients, as the visual cue of methylene blue extraction from aqueous phase to the organic phase is very clear. The chemicals are safe, and routinely used in other school experiments such as ester synthesis (Mayo et al 1994) and the "blue bottle"-demonstration. (Limpanuparb et al 2017) 


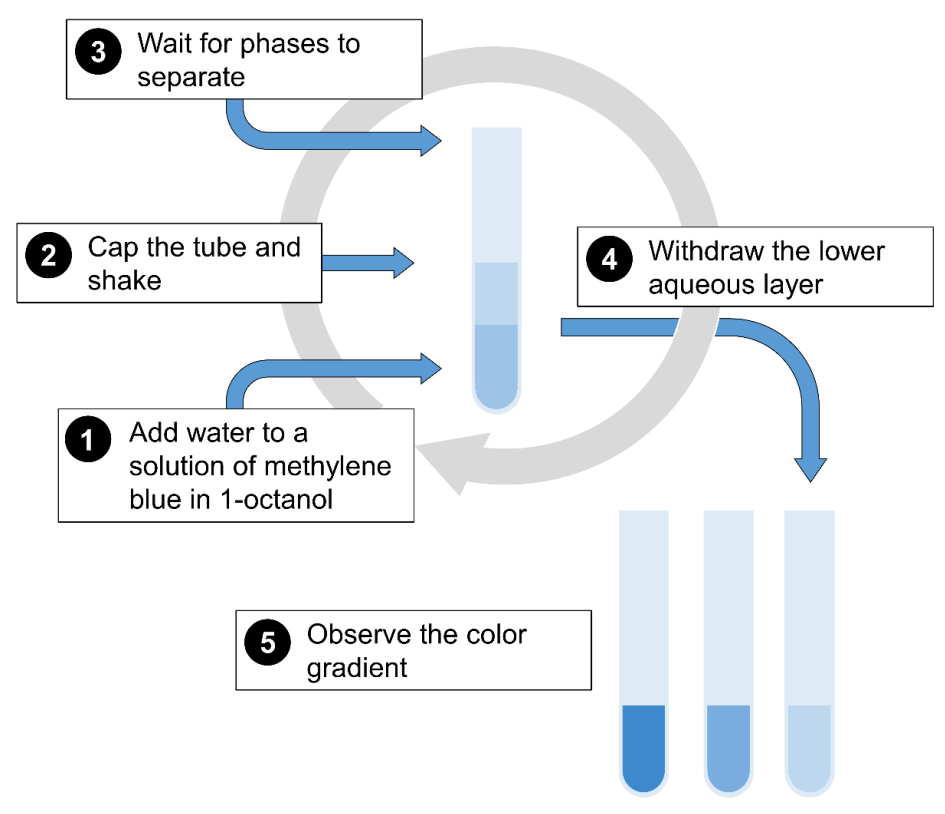

Figure 1: Flowchart of the laboratory experiment developed in this experiment where methylene blue dye is consecutively partitioned between 1-octanol and water.

\section{Questionnaire and respondents}

We set out to assess how university, and upper secondary school students perceived extraction in general, and then via this laboratory experiment, and how the experiment changed their conceptual understanding of extraction processes. An anonymous questionnaire study was carried out in the autumn of 2020 for two groups: Group A consisted of 17 students on course KEMS701 "Experimental Chemistry in Schools" which is included in the University of Jyväskylä's chemistry education curriculum. While answering the questionnaire was mandatory for all students, taking part in this study was optional. The students typically had studied 25-60 ECTS of chemistry, with different backgrounds (ESI3 questionnaire answer A1). Group B consisted of 22 Schildt Upper Secondary School students during the last quarter of their KEM5 "Chemical equilibrium systems" course. With the differing groups $A$ and $B$ we could compare the answers of future chemistry teachers to those provided by upper secondary school students who have completed most of the Finnish chemistry upper secondary school curricula. In group A, 2/17 people did not want their answers to be used in the study. In group B, $3 / 22$ of the participants were under 18 , and no permission to use data from them was applied for; the remaining 19 allowed the use of their responses. Students were instructed to answer without any help from peers or other resources, but this was not strictly enforced. The data from the questionnaires was collected and processed using the Webropol online form system. Notably, only a single question or a subset of multiple-choice questions was visible at a time, and the respondents could not view or edit their previous answers, as well as not being able to preview any of the later questions. For group A, due to COVID-19 restrictions, everything was done online. The experimental part was also truncated to a pictorial walk-through of the laboratory experiment. The upper secondary school students in group B carried the experiment out themselves in the classroom. 
The questionnaire was divided into three parts to assess if and how the student's perception changed. In the first part the student's prior knowledge and presumptions on the topic were scouted. This was followed by the second part where the extraction experiment was carried out (Group A virtually, group B in-person). Finally, in part three the students were e.g. asked to re-evaluate some of their part one answers and in addition to assess what potentially new ideas and concepts they had discovered. To conclude the study, group A students were provided a new experimental context in which to apply the acquired new insights, and group $B$ students were inquired about equilibrium systems as they pertain to their upper secondary school course. The setup drew some inspiration from the evaluation of the effectiveness of a single physics teaching unit, as published by Kesonen et al (2019), however, it was specifically chosen to try to provide as little extra support in addition to the experimental work as possible, and the questions had stronger focus on inspecting the broader understanding and ability to apply the knowledge, both related to, and gained during, the experiment.

\section{Results and discussion}

To characterize briefly, the questionnaire consisted of a number of open and multiple-choice (one out of three options, except A1, A4, and A5) questions. Those with Q-label were common for both groups, while A- and B-labeled were only presented to the corresponding group. The experimental section was done directly before Q8. Thus, up to Q7 (and B1), the answers are 'pre' and starting from Q8, 'post' experiment. Next we discuss the questions and their background, and the answers received in the order they were presented in the questionnaire, with the exception of post-questions Q10-Q12 and B4, which are grouped together with their corresponding pre-questions Q5-Q7 and B1. Questions A1, A4, A5 and Q13 are discussed in ESI 3 only.

\section{Q1/Q2 "How familiar is extraction as a method to you?" / "When was the last time you encountered an extraction in chemistry?"}

In both groups $A$ and $B$ the answers showed limited self-assessed knowledge when it comes to extraction (Q1), with no students choosing "I know a lot about the subject", mostly people answering they know something (group A 60\%, group B 42\%) or just little about extractions (group A 40\%, group B 58\%). In relation to this, when asked when the students have faced the concept of extraction the last time (Q2), most people (33\% of group A, $89 \%$ of group B) had over a year since they had last had to deal with extractions either experimentally or conceptually. This was especially prominent in upper secondary school, probably due to extraction being studied in the first chemistry course two years prior. The university results show some variation, possibly depending on the other currently ongoing chemistry courses of the respondents. With some prior knowledge on the concept of extraction, the groups were well suited for this study, as it allowed us to gain insights into their current understanding as well as monitor their development and accompanying reconceptualization processes.

\section{Q3 "How much do you know about chemicals accumulating in food-chains?"}

The question was used to assess if the students were familiar with some of the more interdisciplinary concepts related to extractions and mass-transfer. The upper-secondary school group B self-assessed their knowledge on such bioaccumulation processes to be 
higher than university students in group $A$. The only students $(11 \%)$ claiming that they know a lot about the subject were from group $B$, where the most common answer also was "I know something" with $53 \%$ of the answers, while in group $A$, the most common answer was "I know only little" $(63 \%)$.

\section{Q4 "What examples of extractions can you think of?"}

The results present a difference between groups: group $A$ of university students was better at coming up with concrete examples; only two students were unable to provide any examples of extractions. Out of group B upper secondary school students, 10 were not able to come up with any examples. Analysing the answers, a total of 31 different proposed examples of extractions were provided by groups $A$ and $B$. Out of these examples 3 described only what an extraction is without providing a concrete case, 2 described concrete lab experiments (separation of toluene from water; using a solid phase extraction cartridge), and all the rest 26 answers were related to cooking or beverages, specifically 20 being about coffee, tea or both. Interestingly, no examples from biological systems were presented by groups $A$ nor $B$. These examples provided by the students both at university and high-school level were highly in line with the hypothesis we had at the outset of this study: students associate extraction with concrete processes that in fact involve several other physicochemical processes than just extractions. This is also in line with the regular usage of kitchen as a context for chemistry studying (e.g. Nuora \& Välisaari 2019). When reflecting this against views of "use of context" in chemical education as described by Gilbert (2006), it is evident that themes of environmental chemistry are often not as tightly connected with the lives of students as e.g. kitchen chemistry; however, the lack of diversity in questionnaire responses highlights the importance of providing more interdisciplinary connections of extraction processes to the students, an aspect of "context" that environmental topics can be argued to be specifically suited for.

\section{Q5/Q10 "How would you describe extraction, as briefly as possible?"}

In Q5 we were interested to see how students would describe extraction as a process. We coded these answers as correct when the students correctly combined the concepts of "solubility" and "separation method". The proportion of correct answers was $40 \%$ for group A and $32 \%$ for group $B$ in the pre-test and rose to $73 \%$ and $47 \%$, respectively, in post-test. Notably, only mentioning "separation method" was particularly common in group B $(42 \%$ and $47 \%$ in pre- and post-test, respectively), while the division between only separation or solubility was more even in group A. Q5 was particularly useful in gaining insights to the misconceptions and predispositions that the students had regarding extraction processes. These answers ranged from almost textbook definitions such as: [Students' answers translated from Finnish by the authors] "Chemical separation method, where the desired substance can be separated from a solution by the substance's solubility properties" (Group $B)$ to several where different methods have been confused with one another: "Extraction is used to evaporate/filter some desired substance away, to [sic] pure product." (Group B). While the definitions provided by the university student group A were on average slightly more correct than group B, such as "Extracting means separation of two substances. Separation is based on the differing solubilities of the substances. (group A)", similarly to upper secondary school student answers, misconceptions and confusion between processes 
were also seen: "extracting means transfer of flavor and color from solid matter to liquid, so that after the solid matter is removed, there is flavor and color in the liquid. (group A)".

The answers provided by both groups A and B in the post-lab answers to Q5 showed improvement, and the accurate use of chemically correct terminology was clearly improved. Furthermore, all post-lab answers to Q10 provided at least one of the key-words coded to be correct (vide supra) in both group A and group B. In several cases deeper insights were clearly developed through the laboratory example. A student of group A whose pre-lab Q5 answer was "Substance is 'dipped' in liquid, so compounds transfer from the substance to the liquid", in the post-lab answer showed a significantly more chemically exact definition with correct terminology: "When two substances (at least one of them a liquid) form two separate phases and they are mixed, chemical compounds can solute at least to one of them (liquid) (polar to polar, nonpolar to nonpolar). If the phases can be separated again and the liquid phase takes solvated compounds from the other phase, it is an extraction." Similar cognitive development is demonstrated by a post-lab answer by a group A student highlighting internal dialog in their answer: "Separation method based on a substance's different solubilities between two phases. It occurred to me just now that maybe the previous experiment had a polar and a nonpolar phase, and that was the trick." It's noteworthy that concept of polarity was not specifically named in the questionnaire or laboratory experiment, showing that the lab project resulted in students being able to constructivistically make key connections to prior knowledge (Ural 2016, Reid \& Shah 2007). In particular, even answers that did not invoke exact chemical terminology showed that students retained the key concept of the experiment on a macroscopic conceptual level (Johnstone 1991, Gabel 1999): "It means that things can be separated from a substance based on their solubilities. For example, in the previous example, methylene blue was soluble in water, so water could be used to separate it from 1-octanol." Talanquer (2011) has argued that one shouldn't view a submicroscopic level as a definitive requirement for proper comprehension of chemical models, and instead presented the concepts of empirically observed experiences, and the translation of such to models by connecting the observations with the relevant scientific concepts. Within these characterizations, it is evident that even e.g. the previously cited answer is more sophisticated than a mere 'experience', and manages to make out relevant connections to chemical phenomena. Further, as extraction is covered relatively early on in the Finnish upper secondary curriculum, and the effect of molecular structure on solubility being a topic only in a later course (Finnish National Agency for Education, 2019), few contact points with submicroscopic level knowledge are available for students at that time. However, we believe the observed conclusions by students, where e.g. a connection to polarity is noted, demonstrate the potential the presented experiment carries for bringing coherence between various levels of prior knowledge.

\section{Q6/Q11 "Is extraction related to brewing coffee? If yes, how?"}

While planning the questionnaire, we anticipated that brewing coffee would be the single most prominent example of extraction processes, which was indeed the case (vide supra). For this reason we wanted to assess how well students actually understood how brewing coffee was actually interconnected to extractions, and in Q6 we asked the students if, and how, extraction is related to brewing coffee. 
The answers highlighted that although macroscopically correctly describing the process, some of the students in group A did not use chemically extract terminology of "solubility", and resorted to speaking of "loosening up" the material. Interestingly, some of the student answers highlight the problems associated with using everyday examples, such as brewing coffee, as examples in natural sciences. Albeit familiar to the students, these examples often involve combinations of multiple phenomena, such as heating, filtration and extraction. The difficulty is observable especially in answers such as "Brewing coffee is an extraction, as coffee grounds are separated from liquid" (Group A) and "no, brewing coffee is filtering" (Group B). (Barker 2000, Treagust et al 2000, Childs et al 2015) Comparing these to the post-experiment answers, the number of students from group $B$ who answered that brewing coffee has nothing to do with extracting dropped from 7 to 2. Notably, these were the numbers despite brewing coffee being the most prominent example of extractions in Q4. Unlike the marked change in the upper secondary school group $B$, university level students in group A were able to correctly describe brewing coffee as an extraction process, at least on a macroscopic level, in both pre- and post-lab questions.

\section{Q7/Q12 "Is extraction related to the accumulation of pollutants in food-chains? If yes, how?"}

To see how students would connect extraction processes in a context familiar only through other disciplines, and not everyday examples, we asked the students to assess how extraction processes are involved in the accumulation of pollutants in food-chains. In their pre-lab answers both groups $A$ and $B$ had mostly limited answers to the question, showing the lacking understanding of any meaningful connection. Even after completing the laboratory experiment, several students $(21 \%$ of all the respondents) were still uncertain about this question. However, we found that a number of students in both groups $A$ and $B$ ( $47 \%$ and $16 \%$, respectively) were adequately either able to make and explain the connection between the accumulation of pollutants and the migration of chemicals in extraction processes, or describe how extraction could be used as a research method to gain insight on the subject. Including such open-ended questions to pre- and post-labs allows students to broaden their views of chemistry, as well as see the interdisciplinary connections chemistry has as the central science. (van Engelen et al 2007; Reid \& Shah 2007, Cresswell \& Loughlin 2017) The fact that such contexts have seen limited use in chemistry possibly stems from the fact that environmental sciences are not a separate subject in Finnish upper secondary school curriculum (Finnish Board of Education 2019). However, since expert lectures have been found to be a good practice (Nurmi et al 2021), taking advantage of the active environmental science research done also in Finnish universities and research institutes and e.g. integrating as project-based education would likely be a feasible way to bring additional insights into studying of these topics in upper secondary schools.

\section{B1/B4 "Is extraction related to chemical equilibrium? If yes, how?"}

B1 and B4 were a pair of pre-post questions for the upper secondary school group, about if extraction is somehow related to chemical equilibrium. The open answers can be characterized as 53\% 'yes', 5\% 'no' and 42\% 'I don't know' in pre-test, and 58\% 'yes', 5\% 'no' and $37 \%$ 'I don't know' in post-test. Answers were typically very short, with 2 students 
(11\%) correctly describing extraction as an equilibrium process in pre-test, and multiple respondents stating that they are related, but can't quite specify how. This indicates that students recognize that extractions are somehow related to chemical equilibrium processes. While we did not pursue this direction further in the present work, with more instructor support the two concepts could be easily tied together for a more holistic and coherent view of the both. As such, this provides a natural extension to the experiment as a tool for introducing dynamic chemical equilibria. Talanquer (2011) described the chemistry knowledge types of "model" and "visualisation", specifying that one can be proficient in manipulating chemical equations without having any perception of their connection to real-world phenomena. The Finnish upper secondary school chemistry course 'Chemical equilibrium systems' (Finnish National Agency for Education, 2019) is arguably heavy on mathematical models and calculations, and has the most scarce connections to the students' everyday lives. Therefore, such a visual experiment could have a notable role in bridging visualisations with models and also experiences, as defined by Talanquer.

\section{Q8 “Did you come up with more examples of extractions during the experiment?"}

We were interested if carrying out and observing the extraction process of the experiment would then allow students to come up and identify other processes that could be considered extractions. Students were indeed able to come up with a plethora of exciting examples, which could serve as great teaching resources, while still being familiar to the students at this level. This also somewhat answers the problem of 'signal' and 'noise' as described by Johnstone (1991): Since the examples have been come up by students with limited knowledge of the subject, they are to be expected to be more straightforward and more likely to be perceived as intended by other students. Examples that students came up with varied from a range of topics, including "washing a paint-brush" and "dyeing clothes". These are examples of processes that do not involve other macroscopic phenomena, such as filtration or boiling, apart from extraction and are, as such, readily useful in further teaching. On the other hand, several unfitting examples were also suggested - e.g. "dilution of watercolors in water" - which mark different types of process, as well as examples that showed conceptual confusion and connections made to extractions carried out using a separatory funnel: "adding a heavier or a lighter substance". Assessing the post-experiment example discovery by the students, we believe that revisiting the more complicated examples, e.g. brewing coffee, later, after the student has gained more insight on relevant chemical phenomena, and on the 'big picture' via e.g. the experiment described in this work, would be beneficial.

\section{Q9 "Do you understand more about extractions now than before the experiment?"}

In Q9 we asked to self-assess if the students understand more about extraction than before starting the experiment. Most (70\%) found to understand somewhat more, with $18 \%$ 'no' and $12 \%$ 'a lot more'. 'No' made up a notable fraction of group A (33\% of group A answers), and 'a lot more' was more prominent in group B (16\% of group B answers). It can be theorized that in addition to the actual format of the work, the answers here, as well as in Q3, have been affected by different perceptions of "understanding something" between upper secondary school and chemistry teacher students. Although we are not aware of any work exploring such a phenomenon, e.g. the lack of correlation between students' perceived 
understanding and their exam scores on corresponding chemistry concepts as reported by Read et al (2004) suggest that existence of such would not be surprising.

\section{B2 "Do you understand more about chemical equilibrium now than before the experiment?"}

Upper secondary school students were asked if they understand more about chemical equilibrium and equilibrium constants after having completed the experiment. Although most responded 'no' (68\%) and none selected 'a lot better', $32 \%$ of the students chose 'somewhat better', even though not even the word 'equilibrium' had been mentioned in any of the materials, possibly signaling the potential of the described laboratory experiment to provide visual support to understand equilibria and other related phenomena.

\section{B3 "How interesting do you find the topic of chemical pollutants in the environment?"}

When asked, upper secondary schools viewed the behaviour of pollutants in the environment as somewhat $(89 \%)$ or very interesting $(11 \%)$. This result is expected: as previously discussed, pollution counts as of the planetary boundaries, and unsurprisingly many young students hold a deep concern over environmental problems we are facing today and in the future. These observations further support using environmental chemistry as a context in chemistry studies.

\section{A2/A3 Post-assignment on food dyes / "Did the previously presented experiment help you in your observations and conclusions in this assignment?"}

A2 and A3 were a post-questionnaire assignment for university course students. In the questions we aimed to assess the students' retention and application of the previous knowledge in a new context. (Reid \& Yang 2002, Teichert et al 2017) The students were provided with a photo taken of 4 different food dyes which were dissolved in 1-octanol and extracted once with water (ESI 2). This photo clearly showed the different partitioning of the food colors between the four dyes in the 1-octanol and water layers. Accompanying the photo, the students were also provided with the common names for each of the dye components. No specific information about their molecular structures was provided. The photo was also supported by a short paragraph describing how all four dyes have been extracted as in the previous experiment. In question A2 the students were then asked to make observations based on the above-described material, "e.g. based on the visible phase boundaries and shades of colours", and asked if they can, based on the observations, deduce something about the properties of each of the colourant compounds.

One of the students responded not comprehending the question; of the remaining 14, every one noticed the yellow being somewhat different to others, of which 12 suggested an explanation for, and of which 8 the authors assessed to be correct. Interestingly, in several of the explanations we deemed incorrect, it seemed that the student had presumed that one of the phases is water and one is pure food dye, even though both the previously shown laboratory experiment and the description of the question clearly noted that the dye is solvated in 1-octanol. We see this as a somewhat clear indication of liquid-liquid extraction being a relatively unfamiliar concept even for students who have completed their first year of university level chemistry curriculum. This misinterpretation of the provided data can also be 
seen to bear similarities to the lack of microscopic level understanding in experimental work as described by Gabel (1999).

Most student observations focused on the yellow dye, which the ingredient list described to contain carotenoids, as it was partitioned almost equally between water and octanol and no clear phase boundary was visible. One student noted the extraction of the yellow dye being harder than other dyes due to the relatively equal partitioning between the phases, and two students connected the fat-solubility of yellow with their previous knowledge of carotene and other fat-soluble compounds being stored in the human body for longer. Some of the students also presented suggestions on the order of partitioning for the other dyes, and some noted that anyhow a notable fraction of each colour is transferred to the water already in the first extraction. In general, the students were able to make relevant macroscopic observations, but only some of the students made an effort to provide chemical reasoning to explain these observations. In addition, the observations dealt practically completely with the order of partitioning between different dyes, suggesting that the students preferred to make only the most obvious possible observations available. However, many other observations could also have been made, e.g. one of the dyes being a mixture of multiple different dye compounds and this possibly being visible in the partitioning, and the differences between colors visible in inner surfaces of the test tubes and stoppers, potentially results of different interactions with glass and plastic. With the well-known merits of guided inquiry and observations in science education (McKee et al 2007, Ural 2016), we believe that encouraging and directing students to make such additional observations will bring them valuable insights and experiences for teaching science themselves, and also for encountering unexpected-but-correct student responses (Furtak 2006). In summarum, we see this kind of post-lab "derivative assignments" could help guide students to observe connections with the newly learned and their observations,(Reid \& Shah 2007) and constructively see connections with prior knowledge, as was the case with the yellow carotenoids dye in these answers. (Gilbert 2006, King 2012)

In question $\mathrm{A} 3$, where we asked if the previously presented experiment helped the students to make these observations, the answers were 13\% 'didn't help at all', $60 \%$ 'helped somewhat', and $27 \%$ 'helped a lot'. Notably, both of the students of the group A that had replied to have encountered extraction somewhere just recently, replied that the experiment helped a lot in making the observations, and their answers in A2 were also assessed by the authors to be among the most conscious ones. A possible interpretation of this is, that with the topic being more strongly in the working memory, less cognitive effort was spent to retrieve previous knowledge from long-term memory; thus background for creating better understanding and applying the knowledge was potent. (Reid \& Yang 2002)

\section{Conclusions}

In summary, we have identified that there is a clear lack of connection between extractions and their real-world contexts in the current chemistry curriculum. We have addressed this discrepancy by developing a simple, affordable and easy-to-carry-out student experiment which involves the repeated partitioning of methylene blue between 1-octanol and water. The experiment uses safe chemicals that are already found in many upper secondary school chemistry stockrooms, and does not require any specialized glassware apart from pipettes 
and test-tubes. Because of its operational simplicity, the experiment was easily carried out in just 30 minutes by a class consisting of 22 upper secondary school students. The experiment is easily adaptable to accommodate for further studies, such as studying why multiple extractions with smaller volumes of solvent are more efficient, calculating the partition coefficient based on the absorption of methylene blue, and also in turn providing a feasible starting point for introducing the concept of dynamic chemical equilibrium.

The associated questionnaire answers demonstrate several chemical misconceptions that we were anticipating at the outset of this study, which we also see as an interesting example of problems that might arise when everyday examples are used in chemistry education. In particular, the current approach of teaching extractions through contextualized examples (i.e., almost entirely in the context of cuisine) and observed challenges in understanding liquid-liquid-extraction as a process even at university level, would suggest that more focused laboratory experiments will help students to gain better understanding and develop connections between fundamental chemical concepts and extractions.

In particular, as a solution to the problems caused by difficult-to-grasp and siloed examples, the developed simple experiment allowed students to reflect and reconceptualize their understanding after carrying out a tangible laboratory experiment. Although concise, the self assessment answers suggest that the presented laboratory experiment, with the accompanying questionnaire, was indeed seen to help understand extraction better. The pedagogical value of the experiment is further supported by the development that we interpreted to happen in various open answers between the corresponding pre- and post questions, which, although include some, are not limited only to recollection of previously learned terminology. One should also note that we aimed the experiment to be as objective as possible. No additional teacher support was given and the students worked alone (group A) or in small groups (group B) based on the student instruction materials presented in the ESI. In a normal lesson, the discussion and guidance from instructors are expected to be a clearly positive factor. In addition to direct learning outcomes, the experiment also led students to come up with new everyday examples of extractions. As these examples are student-discovered, they are expected to be much more relevant than standard text-book ones. In particular, the best examples were generated by university level students who had enough time to think about the concepts more deeply. Tapping into this type of student-led discovery process for practical connections in chemistry education is likely a very valuable tool, and as such should be pursued further. This approach ensures that the examples are meaningful and connected to student's lives, and therefore could provide a much more solid basis for experience-based chemistry education. Such discovery of relevant teaching examples by students we coin student-led concept discovery.

In addition to everyday examples, the results show that students showed interest in environmental chemistry topics, which are very often overlooked in upper secondary school chemistry education. As environmental chemistry is highly connected to the fundamental concepts of extractive processes, such as phase partitioning, numerous relevant interconnections could be used in education. With environmental pollution being acknowledged as one of the major environmental problems facing humanity, and viewed as an interesting topic by students, such interdisciplinary connections are highly beneficial and help chemistry students understand our modern interdisciplinary world by providing skills needed for scientific literacy. 


\section{Acknowledgements}

Tuomas M.A. Nurmi acknowledges financial support from LUMA Centre Finland and Maj and Tor Nessling foundation during the research. Juha $\mathrm{H}$. Siitonen acknowledges financial support from the Osk. Huttunen foundation. The authors express their gratitude to Jaakko Siika-aho for initial feedback on the questionnaire, to the teacher of the university course, Jouni Välisaari, for support in collecting the data, and to the teacher of the upper secondary school course Lassi Korhonen, for support in collecting the data and providing insightful real-world-experience-based comments on an early version of this work.

\section{Author Contributions}

Tuomas M. A. Nurmi: Conceptualization, Methodology, Investigation, Data Curation, Writing - Original Draft, Writing - Review \& Editing

Juha H. Siitonen: Conceptualization, Writing - Original Draft, Writing - Review \& Editing, Visualization

\section{Conflicts of interest}

There are no conflicts to declare.

Electronic Supplementary Information (ESI) available: S1 "Extraction of methylene blue from 1-octanol with water" - Student's guide, S2 "Extraction of methylene blue from 1-octanol with water" - Instructor's guide, S3 Questionnaire questions and response data.

\section{Details of the chemistry textbooks assessed}

- Leena Kaila, Pekka Meriläinen, Päivi Ojala, Petri Pinko. Reaktio 1, Tammi 2009, ISBN 978-951-31-5297-0

- Minna Ikonen, Maiju Tuomisto, Päivi Ojala. Ilmiö 7-9, Sanoma Pro 2016, ISBN 978-952-63-1977-3

- Kalle Lehtiniemi, Leena Turpeenoja. Mooli 1, Otava 2016, ISBN 978-951-1-28095-8

- Arto Liljeblad, Ove Molander, Leena Turpeenoja. Mooli 1-2, Otava 2021, ISBN 978-951-1-35307-2

\section{References}

Barke, H. D., Hazari, A., \& Yitbarek, S. (2009). Misconceptions in chemistry: Addressing perceptions in chemical education. Springer-Verlag Berlin Heidelberg. https://doi.org/10.1007/978-3-540-70989-3

Barker, V. (2000). Beyond appearances: Students' misconceptions about basic chemical ideas. A report prepared for the Royal Society of Chemistry. Available at http://citeseerx.ist.psu.edu/viewdoc/download?doi=10.1.1.649.3454\&rep=rep1\&type=pdf

(20th September 2021) 
Bolong, N., Ismail, A. F., Salim, M. R., \& Matsuura, T. (2009). A review of the effects of emerging contaminants in wastewater and options for their removal. Desalination, 239(1-3), 229-246. https://doi.org/10.1016/j.desal.2008.03.020

Childs, P. E., Hayes, S. M., \& O'Dwyer, A. (2015). Chemistry and everyday life: Relating secondary school chemistry to the current and future lives of students. In Eilks, I. \& Hofstein, A. (eds.) Relevant chemistry education - from theory to practice (pp. 33-54). Sense Publishers, Rotterdam. https://doi.org/10.1007/978-94-6300-175-5 3

Cook, M. P. (2006). Visual representations in science education: The influence of prior knowledge and cognitive load theory on instructional design principles. Science Education, 90(6), 1073-1091. https://doi.org/10.1002/sce.20164

Cresswell, S. L., \& Loughlin, W. A. (2017). A case-based scenario with interdisciplinary guided-inquiry in chemistry and biology: Experiences of first year forensic science students. $\begin{array}{llll}\text { Journal of Chemical } & \text { 1074-1082. }\end{array}$ https://doi.org/10.1021/acs.jchemed.6b00827

DeBoer, G. E. (2000). Scientific literacy: Another look at its historical and contemporary meanings and its relationship to science education reform. Journal of Research in Science Teaching: The Official Journal of the National Association for Research in Science Teaching, 37(6), 582-601. https://doi.org/10.1002/1098-2736(200008)37:6<582::AID-TEA5>3.0.CO:2-L

van Engelen, D. L., Suljak, S. W., Hall, J. P., \& Holmes, B. E. (2007). Undergraduate introductory quantitative chemistry laboratory course: Interdisciplinary group projects in $\begin{array}{llll}\text { phytoremediation. Journal of Chemical Education, } & \text { 84(1), } & 128 .\end{array}$ https://doi.org/10.1021/ed084p128

Finnish National Agency for Education (2019). Määräykset ja ohjeet 2019:2a: Lukion opetussuunnitelman perusteet, ISBN 978-952-13-6623-9. [Corresponding English document, National Core Curriculum for General Upper Secondary Education 2019, ISBN 978-952-13-6677-2, available

at https://verkkokauppa.oph.fi/EN/page/product/national-core-curriculum-for-general-upper-sec ondary-education-2019/2763815

Furtak, E. M. (2006). The problem with answers: An exploration of guided scientific inquiry teaching. Science Education, 90(3), 453-467. https://doi.org/10.1002/sce.20130

Gabel, D. (1999). Improving teaching and learning through chemistry education research: A look to the future. Journal of Chemical education, 76(4), 548. https://doi.org/10.1021/ed076p548

Gilbert, J. K. (2006). On the Nature of "Context" in Chemical Education. International Journal of Science Education, 28(9):957-976. https://dx.doi.org/10.1080/09500690600702470

Herzig, R., Lohmann, N. \& Meier, R. (2019): Temporal change of the accumulation of persistent organic pollutants (POPs) and polycyclic aromatic hydrocarbons (PAHs) in lichens 
in Switzerland between 1995 and 2014. Environmental Science and Pollution Research, 26(11):10562-10575. https://dx.doi.org/10.1007/s11356-019-04236-9

Horowitz, G. (2003). A discovery approach to three organic laboratory techniques: extraction, recrystallization, and distillation. Journal of Chemical Education, 80(9), 1039. https://doi.org/10.1021/ed080p1039

Johnstone, A. H. (1991). "Why Is Science Difficult to Learn? Things Are Seldom What They Seem" Journal of Computer Assisted Learning, 7, 75-83. https://doi.org/10.1111/j.1365-2729.1991.tb00230.x

Kesonen, M. H. P., Leinonen, R. \& Asikainen, M. A. (2019). Applying a simple model aiding in understanding the acceleration of a bungee jumper. Physics Education, 54045012 https://doi.org/10.1088/1361-6552/ab1ae8

King, D. (2012). New perspectives on context-based chemistry education: Using a dialectical sociocultural approach to view teaching and learning. Studies in Science Education, 48(1), 51-87. https://doi.org/10.1080/03057267.2012.655037

Limpanuparb, T., Areekul, C., Montriwat, P., \& Rajchakit, U. (2017). Blue bottle experiment: learning chemistry without knowing the chemicals. Journal of Chemical Education, 94(6), 730-737. http://dx.doi.org/10.1021/acs.jchemed.6b00844

Lohmann, R., Breivik, K., Dachs, J., \& Muir, D. (2007). Global fate of POPs: current and future research directions. Environmental Pollution, 150(1):150-165. http://dx.doi.org/10.1016/j.envpol.2007.06.051

Loyo-Rosales, J. E., Torrents, A., Rosales-Rivera, G. C., \& Rice, C. P. (2006). Linking laboratory experiences to the real world: The extraction of octylphenoxyacetic acid from water. Journal of Chemical Education, 83(2), 248. https://doi.org/10.1021/ed083p248

Mayo, D. W., Pike, R. M., \& Trumper, P. K. (1994). Experiment [8C] Esterification by Use of Acidic Resins in Microscale Organic Laboratory: with Multistep and Multiscale syntheses. Third edition. John Wiley \& Sons, New Jersey, USA.

McKee, E., Williamson, V. M. \& Ruebush, L. E. (2007). Effects of a Demonstration Laboratory on Student Learning. Journal of Science Education and Technology, 16, 395-400. https://doi.org/10.1007/s10956-007-9064-4

Milenković, D., Segedinac, M., Hrin, T., \& Cvjetićanin, S. (2014). Cognitive load at different levels of chemistry representations. Croatian Journal of Education: Hrvatski časopis za odgoj i obrazovanje, 16(3), 699-722. https://hrcak.srce.hr/128202

Nuora, P. \& Välisaari, J. (2019). Kitchen chemistry course for chemistry education students: influences on chemistry teaching and teacher education - a multiple case study. Chemistry Teacher International, 2(1), 20180021. https://doi.org/10.1515/cti-2018-0021

Nurmi, T. M. A., Kiljunen, T. K., \& Knuutinen, J. S. (2019). A fugacity model assessment of ibuprofen, diclofenac, carbamazepine, and their transformation product concentrations in an 
aquatic environment. Environmental Science and Pollution Research, 26(1), 328-341. https://doi.org/10.1007/s11356-018-3485-x

Nurmi, T. M. A., Parviainen, P., Virkkula, O., \& Kähkönen, A. L. (2021). LUMA2020 Inquiring and Innovating Together in Central Finland. In Rusek, M., Tóthová, M., \& Vojiřr, K. (eds.) Project-based Education and Other Activating Strategies in Science Education XVIII., 8-15 http://pages.pedf.cuni.cz/pbe/files/2021/05/ProceedingsPBE2020 final.pdf

Nyachwaya, J. M., \& Gillaspie, M. (2016). Features of representations in general chemistry textbooks: a peek through the lens of the cognitive load theory. Chemistry Education Research and Practice, 17(1), 58-71. https://doi.org/10.1039/C5RP00140D

OECD (1995). Test No. 107: Partition Coefficient (n-octanol/water): Shake Flask Method, https://www.oecd-ilibrary.org/environment/test-no-107-partition-coefficient-n-octanol-water-sh ake-flask-method 9789264069626-en (20th September 2021)

Orzolek, B. J., \& Kozlowski, M. C. (2021). Separation of Food Colorings via Liquid-Liquid Extraction: An At-Home Organic Chemistry Lab. Journal of Chemical Education, 98(3), 951-957. https://doi.org/10.1021/acs.jchemed.0c01286

Read, J., George, A., Masters, A., \& King, M. (2004). Students' perceptions of their understanding in chemistry 1 for veterinary science. In Proceedings of Scholarly Inquiry into Science Teaching and Learning Symposium https://openjournals.library.sydney.edu.au/index.php/IISME/article/view/6496

Reid, N., \& Shah, I. (2007). The role of laboratory work in university chemistry. Chemistry Education Research and Practice, 8(2), 172-185. https://doi.org/10.1039/B5RP90026C

Reid, N., \& Yang, M. J. (2002). The Solving of Problems in Chemistry: The more open-ended problems, Research in Science \& Technological Education, 20:1, 83-98, https://doi.org/10.1080/02635140220130948

Rockström, J., Steffen, W., Noone, K., Persson, Å., Chapin III, F. S., Lambin, E., Lenton, T. M., Scheffer, M., Folke, C., Schellnhuber, H. J., Nykvist, B., de Wit, C. A., Hughes, T., van der Leeuw, S., Rodhe, H., Sörlin, S., Snyder, P.K., Costanza, R., Svedin, U., Falkenmark, M., Karlberg, L., Corell, R. W., Fabry, V. J., Hansen, J., Walker, B., Liverman, D., Richardson, K., Crutzen, P., \& Foley, J. (2009). Planetary boundaries: exploring the safe operating space for humanity. Ecology and Society, https://www.ecologyandsociety.org/vol14/iss2/art32/main.html

Sarıtaş, D., Özcan, H., \& Adúriz-Bravo, A. (2021). Observation and inference in chemistry teaching: a model-based approach to the integration of the macro and submicro levels. Science \& Education, 1-26. https://doi.org/10.1007/s11191-021-00216-z

Sweller, J. (1994). Cognitive load theory, learning difficulty, and instructional design. Learning and instruction, 4(4), 295-312. https://doi.org/10.1016/0959-4752(94)90003-5 
Talanquer V. (2011). Macro, submicro and symbolic: The many faces of the chemistry "triplet", International Journal of Science Education, 33(2), 179-195. http://doi.org/10.1080/09500690903386435

Teichert, M. A., Tien, L. T., Dysleski, L., \& Rickey, D. (2017). Thinking Processes Associated with Undergraduate Chemistry Students' Success at Applying a Molecular-Level Model in a New Context. Journal of Chemical Education, 94(9), 1195-1208. https://doi.org/10.1021/acs.jchemed.6b00762

Treagust, D., Nieswandt, M., \& Duit, R. (2000). Sources of students difficulties in learning

$\begin{array}{lcc}\text { chemistry. Educación } & \text { química, } \\ \text { http://dx.doi.org/10.22201/fq.18708404e.2000.2.66458 }\end{array}$

Ural, E. (2016). The Effect of Guided-Inquiry Laboratory Experiments on Science Education Students' Chemistry Laboratory Attitudes, Anxiety and Achievement. Journal of Education and Training Studies, 4(4), 217-227. https://doi.org/10.11114/jets.v4i4.1395

Williamson, J. C. (2021). Liquid-Liquid Demonstrations: Phase Equilibria and the Lever Rule. Journal of Chemical Education, 98(7), 2356-2363 https://doi.org/10.1021/acs.jchemed.0c01517 